\title{
Interactive Effects of BDE-153 and its Metabolite 2,4-DBP on Biochemical Status in Crucian Carp (Carassius auratus)
}

\author{
Guanghua Lu',2, Jianchao Liu2*, Fuhai Zhang ${ }^{3 * *}$, Matthew Nkoom², Donghai Wu ${ }^{2}$ \\ ${ }^{1}$ College of Hydraulic and Civil Engineering, XiZang Agricultural and Animal Husbandry College, Linzhi, China \\ ${ }^{2}$ Key Laboratory of Integrated Regulation and Resources Development, College of the Environment, \\ Hohai University, Nanjing 210098, China \\ ${ }^{3}$ Anhui Environmental Monitoring Center, Hefei 230061, China
}

Received: 5 July 2017

Accepted: 6 August 2017

\begin{abstract}
Polybrominated diphenyl ethers (PBDEs), which belong to the class of brominated flame-retardants, are widely used in industrial products. PBDEs have been detected in varied environmental matrices and they can induce various toxicities such as neurotoxicity, cytotoxicity, and endocrine-disrupting effects in animals. The main objective of this study was to investigate the effects of $2,2^{\prime}, 4,4^{\prime}, 5,5^{\prime}$-hexabromodiphenyl ether (BDE-153), 2,4-dibromophenol (2,4-DBP), and their mixtures on the endocrine system, including acetylcholinesterase (AChE) of brain, ethoxyresorufin-O-deethylase (EROD), glutathione-S-transferase (GST), and superoxide dismutase (SOD) of liver in crucian carp (Carassius auratus). Fish were exposed to BDE-153 (0.2-100 mg/kg in food), 2,4-DBP (0.2-100 mg/ $\mathrm{kg}$ in food), and their mixture for seven days. BDE-153 alone or in combination with 2,4-DBP significantly reduced brain AChE activity and increased liver EROD activity while no significant effects were observed for 2,4-DBP alone. The simultaneously elevated GST and SOD activities were found at higher doses of BDE-153 and 2,4-DBP (alone and in combination), and exhibited obvious positive correlation $(0.76<R<0.89)$. With regards to the induction fold of biomarker responses, 2,4-DBP has a lower toxicity than its parent compound BDE-153. However, the joint effects of BDE-153 and 2,4-DBP were not enhanced with regard to the four enzymatic activities.
\end{abstract}

Keywords: BDE-153, metabolite, Carassius auratus, biomarker

\section{Introduction}

Polybrominated diphenyl ethers (PBDEs) are organic chemicals that have been commonly applied as flame retardants in plastics, textiles, electronic castings, and

*e-mail: jianchao-liu@hhu.edu.cn

**e-mail: zfh168@163.com items containing polyurethane foam that were produced as three major commercial formulations: penta-BDE, octa-BDE, and deca-BDE [1]. Once used, PBDEs are released into natural aquatic systems via different routes and were found in both abiotic and biotic environmental samples over the last decade [2-5]. Moreover, PBDEs as persistent organic pollutants are well known for their persistence, bioaccumulation, long-range transport potential, and toxicity [6-7]. 
Despite their persistence in the environment, PBDEs can undergo biotransformation in wildlife and humans. They can generate metabolites that may be more toxic than their parent compounds, resulting in a serious threat to the biota [8]. Due to the biotransformation of PBDEs, the biogeochemical behavior of these organic compounds is often complicated and variable [9]. Many studies have reported that 2,2',4,4',5,5'-hexabromodi phenyl ether (BDE-153) was one of the major PBDE congeners found in most human and environmental biota [10-11]. It was readily bioavailable and bioaccumulative in biota because of its strong hydrophobic properties $\left(\log K_{\text {ow }}=7.9\right)$ [12]. In mouse studies, BDE-153 was more persistent than 2,2',4,4'-tetrabromodiphenyl ether (BDE-47) and 2,2',4,4',5-pentabromodiphenyl ether (BDE-99), and disrupted spontaneous behavior, impaired learning and memory [13]. In aquatic organisms, BDE-153 accumulated into Daphnia magna and affected its reproductive health [14]. Fish have not demonstrated much ability to form hydroxylated PBDEs. However, they reductively debrominated PBDEs both in vivo and in vitro, and species-specific differences in metabolic rates and products were observed. Zhang et al. found that debromination was not the only metabolic pathway of BDE-153 in the crucian carp, but other metabolic pathways did occur and formed OH-BDEs and bromophenols in the fish [11]. In the crucian carp, debromination is the much more dominant metabolic pathway than hydroxylation, and 2,4-dibromophenol (2,4-DBP) was the lightest molecule of the metabolites [11]. Although most of the metabolites are more polar and consequently easier to eliminate from the body than their parent compounds. Considerable amounts of these metabolites that were retained in the bodies of several species are mostly related to disturbances of hormonal and endocrine systems as they can bind to and interact with several hormone receptors and transport proteins [8].

PBDEs are suspected toxins of the renal, neural, and endocrine systems [15-16]. In an aquatic organism, PBDE exposure has been associated with the nervous system, metabolic function, and oxidative stress. The neurotransmitter catabolism enzyme acetylcholinesterase (AChE) is an essential enzyme in the transmission of the nerve impulse and it is frequently used in aquatic pollution monitoring such as organophosphate and carbamate insecticides. Recent studies have shown that PAHs and PBDEs may also unselectively inhibit AChE activity of mussels and fish [17-19]. Induction of the cytochrome P450 1A (CYP1A) mediated ethoxyresorufinO-deethylase (EROD) activity is a popular biomarker of exposure to aromatic hydrocarbon receptor (AhR) agonists in many vertebrate species. A wide variety of related polyhalogenated aromatic hydrocarbons such as PCBs has been shown to interact with the AhR. Because of their structural resemblance to PCBs, PBDEs could act as inhibitors of EROD activity, thereby obscuring the possible presence of AhR agonist contaminants [20]. In living organisms, the potential of reactive oxygen species (ROS) to damaged tissues and cellular components has a significant interest in environmental toxicology studies. The antioxidant defenses of biological systems including superoxide dismutase (SOD), catalases, glutathione peroxidases, and glutathione S-transferase (GST) play important roles in detoxifying harmful ROS and/or xenobiotics. Moreover, GST, a phase II metabolic enzyme involved in the conjugation of glutathione enzyme with contaminants, protects cells against toxic effects and oxidative stress. Changes in CYP1A enzyme, GST, and SOD activities following exposure to either individual or mixed PBDEs congeners have been observed in fish [21-22]. However, changes in the physiological response of fish exposed to PBDEs and their metabolites have not been well studied.

The objective of this study was to investigate the physiological responses of crucian carp (Carassius auratus) after oral exposure to a mixture of BDE-153 and its metabolites 2,4-DBP over a seven-day period. The activities of AChE in the brain, biotransformation enzymes (EROD and GST), and an antioxidant defense enzyme (SOD) in the liver were utilized to evaluate the comparative knowledge on the biochemical effects of BDE-153 and 2,4-DBP (alone and in combination) in the fish, which was useful for recognizing PBDE and their metabolites exposure.

\section{Material and Method}

\section{Chemicals}

BDE-153 (purity $>98 \%$ ) and 2,4-DBP (purity $>99 \%$ ) were purchased from Accustandard Inc (New Haven, CT, USA). Acetylthiocholine iodide (ATChI), 5,5'-dithiobis (2-nitrobenzoic acid) (DTNB), $\beta$-Nicotinamide adenine dinucleotide 2'-phosphate reduced tetrasodium salt (NADPH), and 7-ethoxyresorufin and tricaine methane sulfonate (MS222) were obtained from Sigma Chemical Company (St. Louis, MO, USA), their purity was $>98 \%$. Bovine serum albumin was purchased from Shanghai Huixing Biochemistry Reagent Co., Ltd. (Shanghai, China) and the purity was $>98 \%$. Water was purified using a Milli-Q integral water purification system (Millipore, Milford, MA, USA). Immature crucian carp weighing $21.3 \pm 3.5 \mathrm{~g}$ were purchased from the Nanjing Institute of Fishery Science (Nanjing, China).

\section{Fish Culture and Exposure}

All healthy crucian carp were acclimatized for two weeks in dechlorinated municipal water and fed every day with pellet food ( $6 \%$ of body weight/day). The exposed water quality was checked daily and maintained at conditions suitable for fish $\left(18 \pm 1^{\circ} \mathrm{C} ; \mathrm{pH} 7.2 \pm 0.2\right.$; DO $\left.6.0 \pm 0.5 \mathrm{mg} / \mathrm{L} ; \mathrm{CaCO}_{3} 116.3 \pm 3.5 \mathrm{mg} / \mathrm{L}\right)$. A daily 12/12-h light/dark photoperiod cycle was used throughout the experiment.

Randomly assigned fish were kept in 30-L glass tanks containing $20 \mathrm{~L}$ of dechlorinated tapwater under 
constant aeration. BDE-153 and 2,4-DBP (alone and in combination) were added into the corresponding tanks using dietary exposure regimes. Fish exposure to BDE153 and 2,4-DBP was accomplished via consumption of spiked commercial food pellets. BDE-153 and 2,4DBP were dissolved in $10 \mathrm{~mL}$ of dimethyl sulfoxide (DMSO) to create a nominal concentration in food. For the individual compound experiments, the fish were exposed to eight different treatments, including dietary exposure to BDE-153 or 2,4-DBP at $0.2,2,20$, and $100 \mathrm{mg} / \mathrm{kg}$. The compound mixture experiments consisted of three different binary exposure treatments, including dietary BDE-153 in combination with 2,4-DBP $(0.2+0.2$, $2+2$, and $20+20 \mathrm{mg} / \mathrm{kg}$ ). Control food was prepared by the same method of spiking with the same quantitation of DMSO to the food pellets. Fish dietary exposure to BDE153 and 2,4-DBP were prepared according to Zhang et al. [11]. Fish were fed $0.2 \mathrm{~g} / \mathrm{day} /$ fish of either the spiked food pellets or the control food for seven days. Each treatment was replicated three times simultaneously. To exclude potential background levels of BDE-153 and its metabolites in the food, three representative samples of the original food pellets were analyzed prior to the study. No BDE-153 and its metabolites were detected in any food samples. Following 1, 2, 4, and 7 days of exposure, fish were anaesthetized with MS222 (100 mg/L) and sacrificed by cervical transection. Tissues (liver and brain) were removed immediately, washed in $0.15 \mathrm{M} \mathrm{KCl}$, and frozen in liquid nitrogen until further processing.

\section{Enzyme Assays}

The brain samples $(10 \% \mathrm{w}: \mathrm{v})$ were homogenized in ice-cold buffer $(0.1 \mathrm{M}, \mathrm{pH} 7.2$, triton $0.1 \%)$ and centrifuged at $10,000 \times \mathrm{g}$ for $20 \mathrm{~min}$ at $4^{\circ} \mathrm{C}$. The $\mathrm{AChE}$ enzymatic activity was measured by the method of Guilhermino et al. [23]. $50 \mu \mathrm{L}$ of the homogenate and $250 \mu \mathrm{L}$ of the reaction solution $(1.0 \mathrm{~mL}$ of DTNB $10 \mathrm{mM}$ solution, $0.2 \mathrm{~mL}$ of ATChI $0.075 \mathrm{M}$ and $30 \mathrm{~mL}$ of phosphate buffer) were added to a 96-well microplate. The activity was measured at $30^{\circ} \mathrm{C}$ for $3 \mathrm{~min}$ and expressed as nmol/ $\mathrm{min} / \mathrm{mg}$ protein.

The liver samples $(5 \% \mathrm{w}: \mathrm{v})$ were homogenized in ice-cold buffer $(0.25 \mathrm{M}$ sucrose, $0.1 \mathrm{M}$ Tris-HCl, $1 \mathrm{mM}$ EDTA, $\mathrm{pH}$ 7.4) and centrifuged for $15 \mathrm{~min}$ at 9,000 $\mathrm{g}$ and $4^{\circ} \mathrm{C}$. EROD and GST activities were determined according to the method described by Lu et al. [24]. The EROD activity was determined at $572 \mathrm{~nm}$ by adapting to a microplate reader using $140 \mu \mathrm{L}$ buffer $(0.1 \mathrm{M}$ Tris, $0.15 \mathrm{M} \mathrm{KCl}, \mathrm{pH} 8.0$ ), $10 \mu \mathrm{L}$ of $2 \mu \mathrm{M}$ 7-ethoxyresorufin, and $10 \mu \mathrm{L}$ of the supernatant. The reaction was then initiated at $25^{\circ} \mathrm{C}$ for $30 \mathrm{~min}$ by adding $40 \mu \mathrm{L}$ of $2.1 \mathrm{mg} / \mathrm{mL}$ NADPH. The EROD activity was expressed as $\mathrm{pmol} / \mathrm{min} / \mathrm{mg}$ protein. GST activity was measured at $340 \mathrm{~nm}$ by the addition of $0.15 \mathrm{~mL}$ of the reaction solution $(100 \mu \mathrm{L}$ of $0.1 \mathrm{mM}$ potassium phosphate, $10 \mu \mathrm{L}$ of $1.0 \mathrm{mM} \mathrm{CDNB}, 10 \mu \mathrm{L}$ of $1.0 \mathrm{mM} \mathrm{GSH}$, and $880 \mu \mathrm{L}$ $\mathrm{H}_{2} \mathrm{O}$ ) and $30 \mu \mathrm{L}$ of the homogenate, and was expressed as $\mathrm{nmol} / \mathrm{min} / \mathrm{mg}$ protein. SOD activity was determined by the method of Marklund and Marklund at $420 \mathrm{~nm}$ [25]. $30 \mu \mathrm{L}$ of Tris- $\mathrm{HCl}$ buffer warmed for $10 \mathrm{~min}$ at $25^{\circ} \mathrm{C}$ were added to the microplates; subsequently, $10 \mu \mathrm{L}$ the homogenate and $6 \mu \mathrm{L}$ preheated pyrogallol were added. The rate of pyrogallol auto-oxidation was measured for $3 \mathrm{~min}$. The SOD activities were expressed as U/mg protein. Protein concentrations were determined using the method of Bradford with bovine serum albumin as the standard [26].

\section{Statistical Analysis}

All the data were tested for normality and homogeneity of variance. The results were expressed as mean \pm standard deviation (SD). Differences between the control and the experimental groups were analyzed via analysis of variance (ANOVA) and Duncan's post-hoc test using SPSS statistical package (ver. 17.0, SPSS Company, Chicago, IL, USA). All the differences were considered significant at $P<0.05$.

\section{Results and Discussion}

There was no mortality during the whole experimental period. Also, no significant difference was observed in the enzymatic activities between the fish that were exposed to the solvent and food controls. Thus, for each biomarker, data from the two groups were pooled for further statistical analysis.

AChE activity in the brain of fish at different exposure concentrations and time points is shown in Fig. 1. BDE-153 did not significantly change the AChE activity at any tested concentrations in the early exposure of day 1 . However, AChE activity was significantly inhibited by BDE-153 at all tested concentrations after four days of exposure. After two days of exposure, the decreased levels of AChE activity matched the exposure concentrations increase. A significant AChE activity inhibition was observed at higher concentrations ofBDE-153 $(\geq 20 \mathrm{mg} / \mathrm{kg})$. At the highest concentration of $100 \mathrm{mg} / \mathrm{kg}$, the inhibition of AChE activity exhibited obvious time dependence, and the maximal inhibition rate was close to $50 \%$ at day 7 (Fig. 1a). For the 2,4-DBP of BDE-153 metabolites, AChE activity did not significantly change at all of the exposure concentrations during the entire exposure period (Fig. 1b).

Few studies have addressed the effect of PBDEs on AChE activity in fish brain, and the mechanisms of toxicity are not known. A previous study showed no significant effects of exposure to DE-71 (0.1, 0.5 and $2.5 \mathrm{mg} \mathrm{DE}-71 / \mathrm{kg}$, fed for 10 weeks) on AChE activity in the cerebral cortex of adult ranch minks (Mustela vison) [27] and AChE activity in adult zebrafish (Danio rerio) exposed to environmentally relevant concentrations of DE-71 (0.16, 0.8, and $4.0 \mu \mathrm{g} / \mathrm{L})$ via water for 150 days [18]. However, in our study we found a significant inhibition of AChE activity in the fish after BDE-153 exposure. 
This observation was also found in zebrafish larvae produced from adult zebrafish after 150 days of DE-71 exposure, with a significant inhibition of AChE activity in the larvae [18]. In addition, the degree of inhibition of AChE increased with increasing concentrations (2.5, 5, 10 , and $20 \mu \mathrm{g} / \mathrm{L}$ ) of BDE-47 and BDE-99, and the inhibition effect of BDE-47 is bigger than that of BDE99 [28]. Our results suggest that 2,4-DBP is less toxic than its parent compound BDE-153 due to the biological
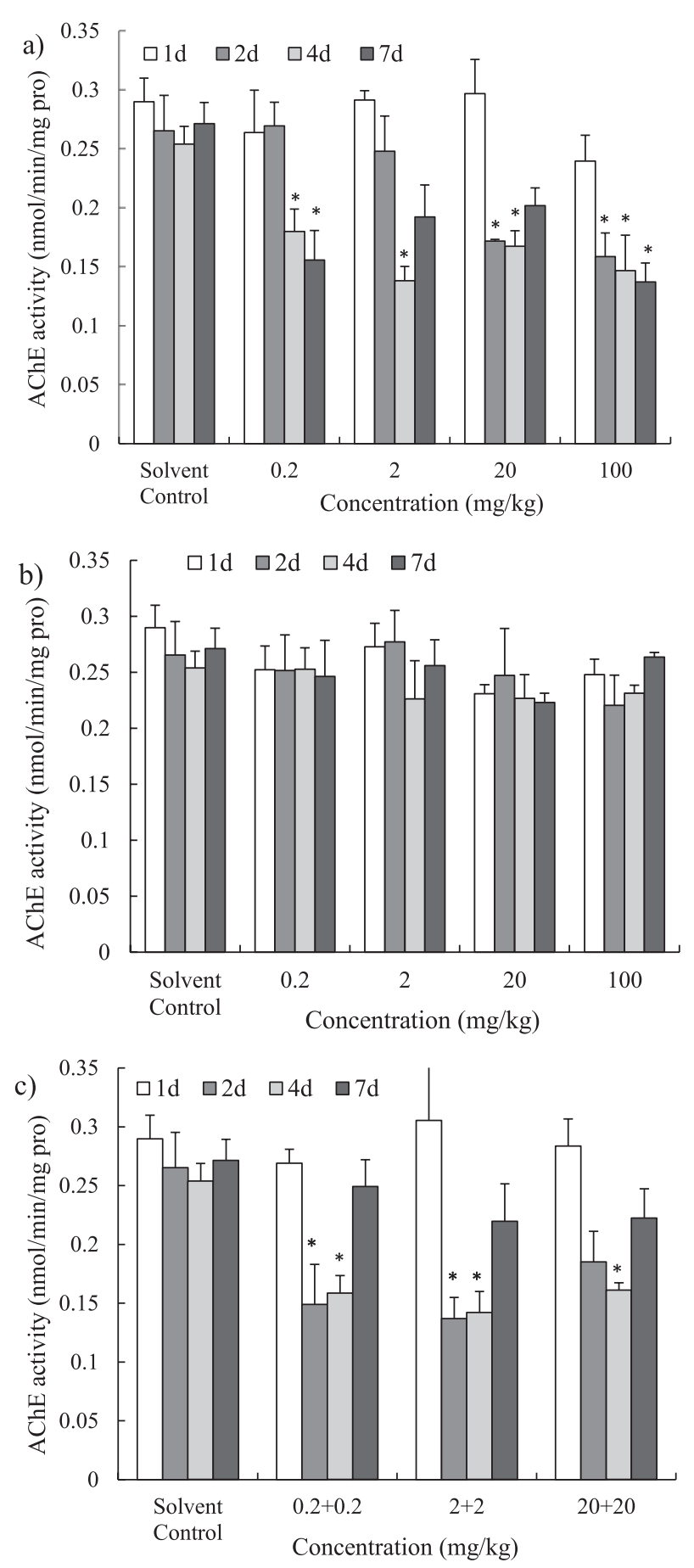

Fig. 1. Changes in AChE activity in fish after exposure to: a) BDE-153, b) 2,4-DBP, and c) their mixture for seven days $(\mathrm{n}=3) . *$ Significant difference from the solvent control $(\mathrm{P}<0.05)$ metabolism function. Or more accurately, brain AChE enzyme is not a major target for 2,4-DBP during the seven days of exposure to low concentrations.

Brain AChE activity did not change obviously at all test concentrations of the mixture at days 1 and 7 . However, AChE activity significantly inhibited at the two lower concentrations of the mixture at day 2. Significant differences in AChE activity were found at all the chemical treatments on day 4 , showing lower activities
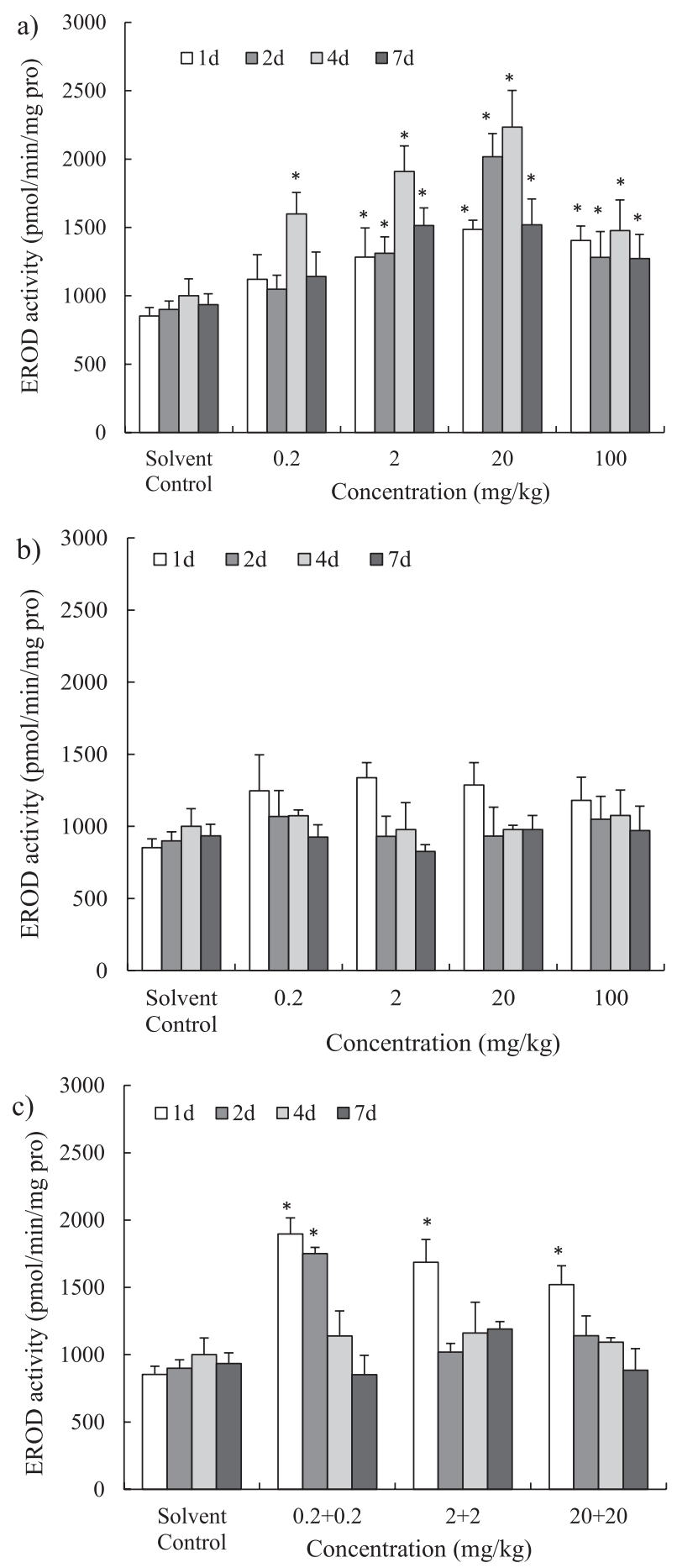

Fig. 2. Changes in EROD activity in fish after exposure to: a) BDE-153, b) 2,4-DBP, and c) their mixture for seven days $(\mathrm{n}=3)$. *Significant difference from the solvent control $(\mathrm{P}<0.05)$ 
$(36.7 \%-49.4 \%)$ than the control group. These results were comparable to the inhibition rates (34.1\%-49.6\%) of AChE activity by single BDE-153. This suggests that the inhibition effect of AChE activity was primarily defined by the prevailing BDE-153, and that AChE activity response to BDE-153 was not markedly downregulated by the addition of 2,4-DBP. The levels of AChE inhibition induced by BDE-153 and 2,4-DBP as single substances and in combination were not significantly different, suggesting different mechanisms of enzymatic response. An inhibition rate of AChE activity by $20 \%$ or more has been considered high enough to induce adverse effects in neurofunction [29]. Decreased AChE activity
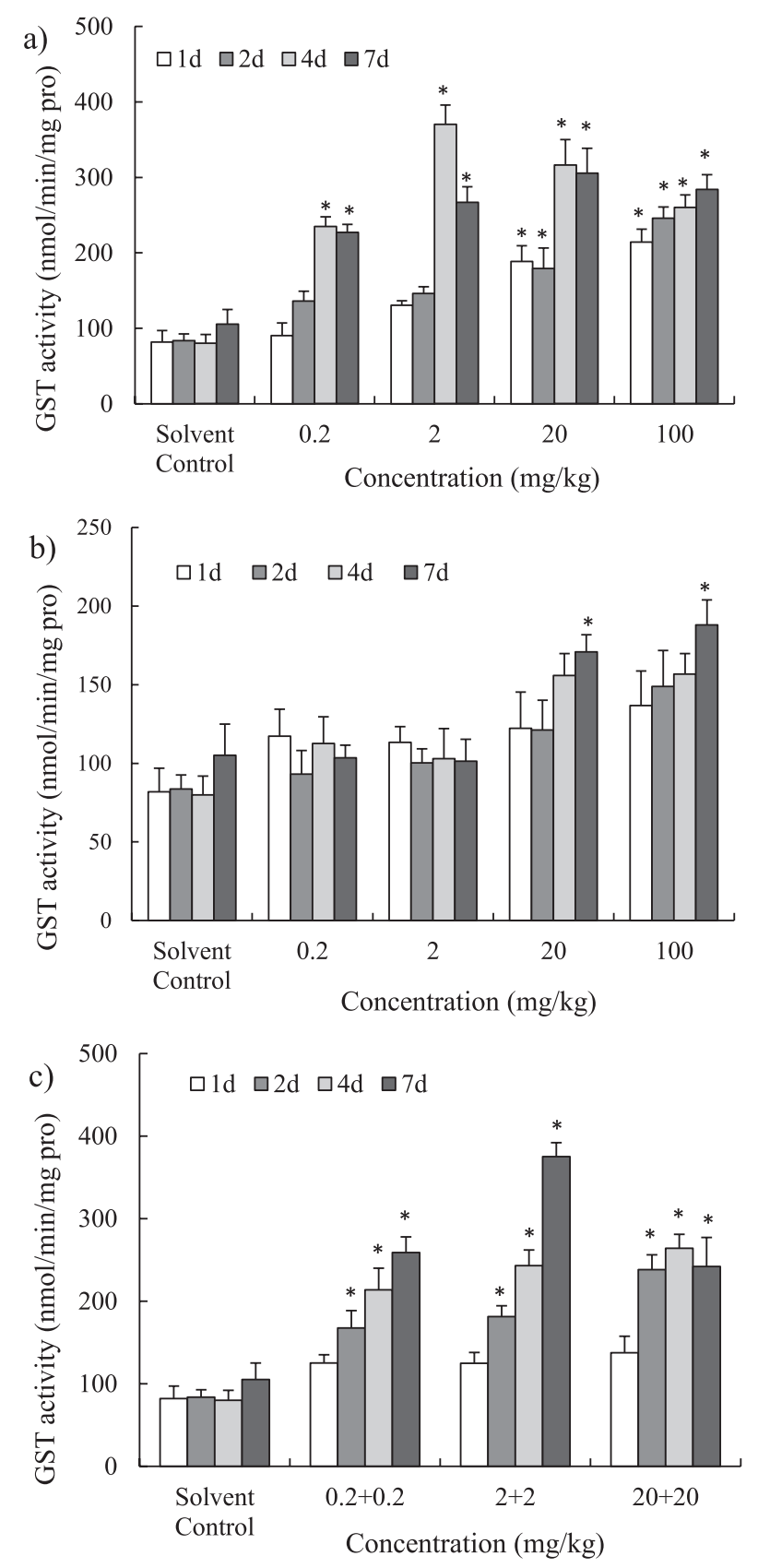

Fig. 3. Changes in GST activity in fish after exposure to: a) BDE153, b) $2,4-\mathrm{DBP}$, and c) their mixture for seven days $(\mathrm{n}=3)$. *Significant difference from the solvent control $(\mathrm{P}<0.05)$ could result in less acetylcholine, which is important for cholinergic neurotransmission. Moreover, $\mathrm{AChE}$ is crucial for controlling several physiological (e.g., growth, reproduction) and behavioural (e.g., swimming) processes that may directly or indirectly influence individual and population fitness [19].

Liver EROD activity was not significantly changed at the lowest exposure concentration $(0.2 \mathrm{mg} / \mathrm{kg})$ of BDE153 during all the exposure period, with the exception of day 4. Significant differences in EROD activity were found in other treatments. In addition, EROD activity induction was most significant at day 4 for all the exposure concentrations of BDE-153, and the induction rates were nearly $47.6-123 \%$ (Fig. 2a). However, the concentration and time-dependence for BDE-153 exhibited the trend of inducing, maintaining, and recovering. This corresponds to the increase in the exposure times and concentrations, which were also found in goldfish exposed to sulfamethoxazole and caffeine [30]. No significant differences among the treatments of 2,4-DBP-alone were found for EROD activity (Fig. 2b). The mixture significantly increased EROD activity at all the tested concentrations at day 1 and the lowest concentration at day 2. However, after the days 4 and 7 of exposure, no significant differences among the treatments were found for EROD activity. The time-response for mixture exhibited the trend of inducing, followed by recovering. Comparing the single exposure of BDE-153 and 2,4-DBP, the maximum induction rates by the mixture occurred faster and were forwarded from days 4 to 1 .

CYP1A is uniformly distributed in fish liver and involved in the metabolism of contaminants such as PAHs, by activation of the aryl hydrocarbon receptor (AhR) in the aryl hydrocarbon pathway within the liver [31]. Therefore, any interaction between xenobiotics and CYP1A-catalyzed activities will likely disrupt hepatic and extra-hepatic xenobiotic metabolism in the fish. The induction of the CYP1A can be assayed as EROD activity [21]. The ability of PBDEs to induce EROD activity was studied in fish, chick, and rat hepatocytes [31-32]. The elevated EROD activity was presumably due to the structural similarities of PBDEs with some dioxin-like compounds such as PCBs. Interactions of PBDE mixtures and individual congeners with AhR have been investigated in previous studies, and BDE-153 was suggested to be a weak AhR-activator in vivo, thus the activated AhR could bind DNA and induce EROD greater activity [31].

The response of liver GST activity during different exposure periods are presented in Fig. 3. GST activity did not change significantly at concentrations equal to or lower than $2 \mathrm{mg} / \mathrm{kg}$ of BDE-153 after days 1 and 2 of exposure. Whereas GST activity significantly increased in the other cases, such as at the two higher concentrations during all the exposure period (Fig. 3a). Lower concentrations of $2,4-\mathrm{DBP}(\leq 2 \mathrm{mg} / \mathrm{kg})$ did not induce GST activity during all the exposure period compared to the controls, but GST activity was significantly increased at the two higher concentrations $(\geq 20 \mathrm{mg} / \mathrm{kg})$ in the 
post-exposure period (Fig. 3b). The maximal induction rate of GST activity was nearly 3.63 -fold at $2 \mathrm{mg} / \mathrm{kg}$ of BDE-153 on day 4, which was obviously higher than that induced by $2,4-\mathrm{DBP}$ of $20 \mathrm{mg} / \mathrm{kg}$ on day 7 with 0.79 -fold of the control. Exposure to 2,4-DBP in this current study resulted in no significant effects on EROD activity. This suggests that the effects of PBDE exposure on hepatic phase II metabolism are more sensitive than those of phase I metabolism. Additionally, the increase in GST activity showed a time-dependent manner at the two higher concentrations of 2,4-DBP, suggesting that GST may play an important role in the detoxification response for 2,4-DBP-exposed fish.
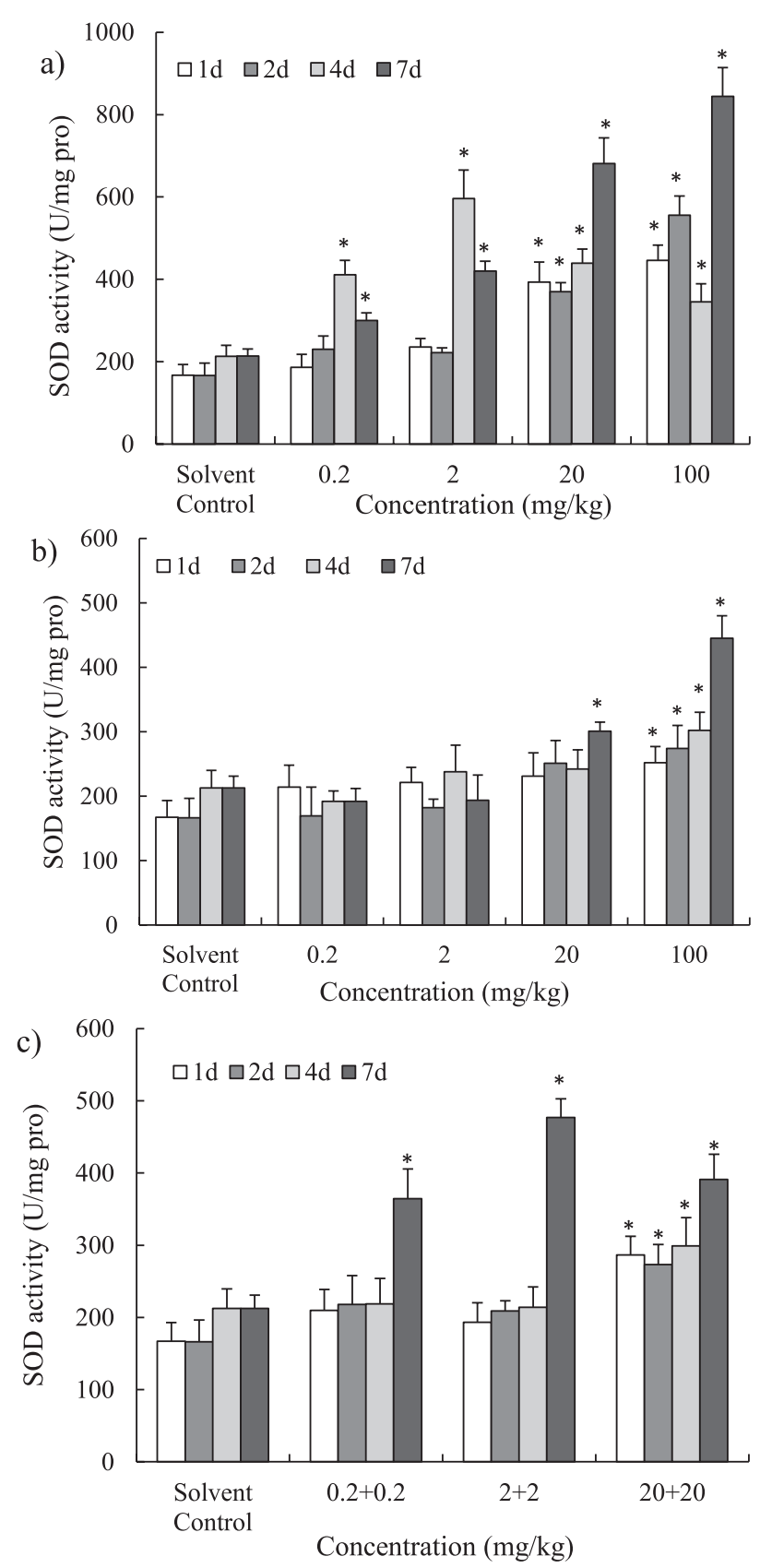

Fig. 4. Changes in SOD activity in fish after exposure to: a) BDE153, b) 2,4-DBP, and c) their mixture for seven days $(n=3)$.

*Significant difference from the solvent control $(\mathrm{P}<0.05)$
The combined exposure of BDE-153 and 2,4DBP significantly modulated GST activity at all test concentrations after 2 days of exposure. At days 2 and 4 , GST activity showed obvious time- and concentrationdependent manners. However, the concentration response of GST activity exhibited the trend of first inducing and then subsequently recovering on day 7 . Thus, the induction rates of GST activity were highest at the mixture concentration of $2+2 \mathrm{mg} / \mathrm{L}$ on day 7 , with 2.57 -fold of the control. Comparing Figs 2c) and 3c), the main finding from this study revealed that EROD activity reached its peak faster than that of GST, suggesting that EROD may
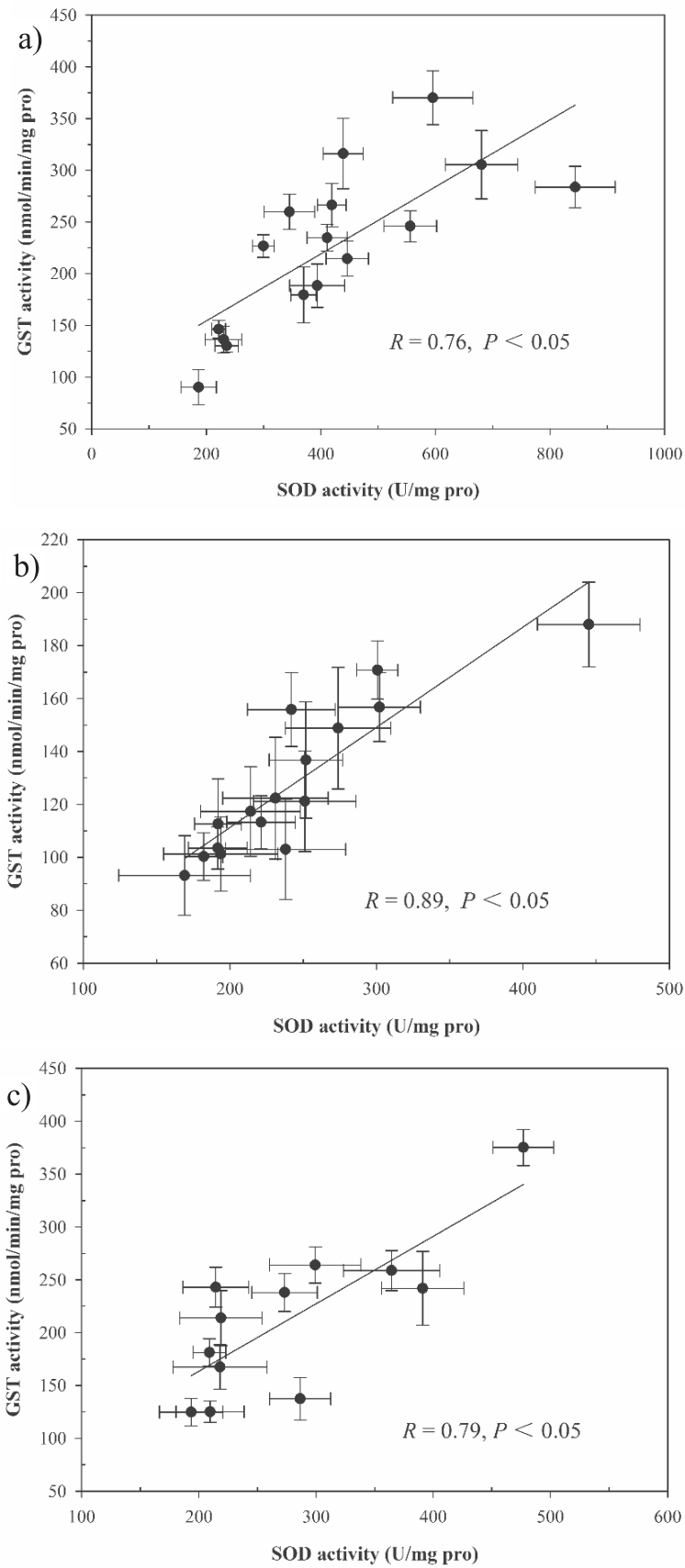

Fig. 5. The relationships between SOD and GST activities in fish exposed to: a) BDE-153, b) 2,4-DBP, and c) their mixture for seven days $(\mathrm{n}=3)$. 
play an important role in the early detoxification response in the PBDE-exposed fish. In addition, considering the time-dependent manner, the maximal induction rates of GST activity by BDE-153, 2,4-DBP, and their mixture occurred on days 2,4 , and 7, respectively, which indicates that the addition of 2,4-DBP did defer the phase II metabolism of BDE-153.

As a phase II enzyme, GST plays vital roles in protecting tissues against oxidative damage of diverse electrophilic endogenous and xenobiotic substrates by way of conjugation with glutathione to produce less toxic and more water-soluble compounds. It is thought that the cytosolic GST are primarily involved in the transportation of compounds, such as thyroid hormone and contaminants like PBDEs, which have structural similarities to thyroid hormones [33]. Recent studies have hypothesized that GST may be involved in the detoxification of PBDEs - possibly via reductive debromination [34-35]. In this study, inductive GST activity was found in most cases, suggesting that cytosolic GST is involved in the detoxification of PBDEs. The elevated GST activity was also observed in the liver of fish that was exposed to PBDE mixture [21, 32]. However, the induction rate of GST activity declined at the highest exposure concentration of the mixture at day 7 , which could be attributed to damage of the liver [36].

SOD catalyzes the breakdown of ROS-causing $\mathrm{O}_{2}{ }^{-}$and is a key component within the primary defensive system against oxidative stress-induced damage. In this present study, SOD activity was significantly increased at concentrations equal to or higher than $20 \mathrm{mg} / \mathrm{kg}$ of BDE-153 during all the exposure period and at the two lower concentrations $(0.2$ and $2 \mathrm{mg} / \mathrm{kg})$ of BDE-153 at days 4 and 7. Lower concentrations of 2,4-DBP $(\leq 2 \mathrm{mg} / \mathrm{kg})$ did not induce SOD activity during all the exposure period compared to the controls, but SOD activity was significantly increased at the highest concentration $(100 \mathrm{mg} / \mathrm{kg})$ of 2,4-DBP during all the exposure period and at a higher concentration $(20 \mathrm{mg} / \mathrm{kg}$ ) of $2,4-\mathrm{DBP}$ in the post-exposure period (Fig. 4b). The mixture significantly increased SOD activity at all tested concentrations on day 7. However, SOD activity was obviously induced at the highest concentration from the first day of exposure until the last day of exposure (Fig. 4c).

The enhanced SOD activity in the liver suggested that oxidative stress was induced and a higher antioxidative capacity was necessary to scavenge ROS when the fish were exposed to BDE-153 and 2,4-DBP (alone or in combination). Similar results were reported in previous studies, where SOD activity was obviously increased in the liver of Carassius auratus exposed to BDE-209, BDE-47, BDE-99, and their mixtures [32, 37]. According to the results of a previous study, the induction of enzyme activities might reflect the attempts of defensive mechanisms to eliminate the highly reactive intermediates produced in the cells, or rather they can be assumed as an adaptive response to counteract the increased ROS generation caused by PBDEs [38]. In addition, BDE-153 can be easily bioaccumulated and shows significant biotransformation via debromination, hydroxylation, and cleavage of the diphenyl ether bond, which indicated evidence of bioavailability of BDE153 from food in the form of debrominated metabolites and oxidative metabolites in fish [11]. The physiological changes observed in antioxidant enzyme activity detected in this study suggest that the low basal metabolic rates and basal oxygen holding capacity may have been disrupted by elevated cellular metabolism and ROS [21].

The correlation between both SOD and GST activity is presented in Fig. 5. In the liver, SOD activities positively correlated with levels of GST activities; the correlation coefficients were $0.76,0.89$, and 0.79 for the exposure of BDE-153, 2,4-DBP and their mixture, respectively. This phenomenon was also observed in the aquatic exposure of BDE-47 where the SOD and GST activities were simultaneously induced in a $100 \mu \mathrm{g} / \mathrm{L}$ BDE-47-exposed group [39]. This simultaneous change between both SOD and GST activities may be interpreted as possible protection by SOD and GST, which could be sensitive to $\mathrm{O}_{2}^{-}$[40]. These results suggest that GST also influences ROS levels as it requires glutathione for detoxification. As mentioned above, BDE-153 and 2,4-DBP (alone and in combination) induced oxidative stress indicated by increased SOD and GST activities in fish. Oxidative stress may damage cells in organisms [39]. Furthermore, the long-term disturbance is likely to disrupt the balance between metabolic rates and aerobic capacity and could potentially affect all the aspects of reproduction - from development to spawning [21].

\section{Conclusions}

This study demonstrated that PBDE exposure to fish resulted in a number of physiological and biochemical effects, including changes in enzyme activities of neurotoxicity biomarker (AChE), detoxification-mediated (EROD and GST), and antioxidant defence marker (SOD). Decreased AChE activity and increased EROD, GST, and SOD activities were observed in crucian carp exposed to BDE-153 and 2,4-DBP (single or in combination), and time- and concentration-dependent were apparent in some cases. The 2,4-DBP showed a lower toxicity than its parent compound BDE-153 in the physiological monitoring indictor, especially for AChE and EROD. All the biomarkers (AChE, EROD, GST, and SOD) yielded high sensitivity to BDE-153. The results suggest that these biomarkers might be useful for ecological risk assessments of PBDEs on fish. However, this study only investigated the responses of four biomarkers, but debrominationrelated enzymes may hold more promise with the evaluation of process influence on bioaccumulation and metabolism. 


\section{Acknowledgements}

This study was supported by the Yarlung Zangbo Scholars of Agricultural and Animal Husbandry College of Tibet University (grant No. 2015XYA01), the National Natural Science Foundation of China (No. 516030611), the National Science Funds for Creative Research Groups of China (No. 51421006), the Fundamental Research Funds for the Central Universities (No. 2015B12114), the Scientific and Technological Project of Henan Province (No. 162102310057), and the Priority Academic Program Development of Jiangsu Higher Education Institutions.

\section{References}

1. MARTELLINI T., DILETTI G., SCORTICHINI G., LOLINI M., LANCIOTTI E., KATSOYIANNIS A., CINCINELLI A. Occurrence of polybrominated diphenyl ethers (PBDEs) in foodstuffs in Italy and implications for human exposure. Food Chem. Toxicol., 89, 32, 2016.

2. GE J., LIU M., YUN X., YANG Y., ZHANG M., LI Q., WANG J. Occurrence, distribution and seasonal variations of polychlorinated biphenyls and polybrominated diphenyl ethers in surface waters of the East Lake, China. Chemosphere, 103, 256, 2014.

3. KIM M., LI L.Y., GORGY T., GRACE J. Review of contamination of sewage sludge and amended soils by polybrominated diphenyl ethers based on meta-analysis. Environ. Pollut., 220, 753, 2017.

4. MATSUKAMI H., SUZUKI G., SOMEYA M., UCHIDA N., TUE N., TUYEN L., VIET P., TAKAHASHI S., TANABE S., TAKIGAMI H. Concentrations of polybrominated diphenyl ethers and alternative flame retardants in surface soils and river sediments from an electronic waste-processing area in northern Vietnam, 2012-2014. Chemosphere, 167, 291, 2017.

5. DU X., CHANG H., ZHOU Y., QIU Y., WU Y., LIN Z., ZHU Z., ZHAO J. Polybrominated diphenyl ethers and its methoxylated analogues in biota and sediment samples from two freshwater lakes in Yangtze River delta. Environ. Earth Sci., 76, 171, 2017.

6. KELLY B., IKONOMOU M., BLAIR J., MORIN A., GOBAS F. Food web-specific biomagnification of persistent organic pollutants. Science, 317, 236, 2007.

7. TANG B., LUO X., ZENG Y., MAI B. Tracing the Biotransformation of PCBs and PBDEs in common carp (Cyprinus carpio) using compound-specific and enantiomer-specific stable carbon isotope analysis. Environ. Sci. Technol., 51, 2705, 2017.

8. WEIJS L., DAS K., SIEBERT U., VAN ELK N., JAUNIAUX T., NEELS H., BLUST R., COVACI A. Concentrations of chlorinated and brominated contaminants and their metabolites in serum of harbour seals and harbour porpoises. Environ. Int., 35, 842, 2009.

9. VONDERHEIDE A., MUELLER K., MEIJA J., WELSH G. Polybrominated diphenyl ethers: Causes for concern and knowledge gaps regarding environmental distribution, fate and toxicity. Sci. Total Environ., 400, 425, 2008.

10. STAPLETON H., KELLY S., PEI R., LETCHER R., GUNSCH C. Metabolism of polybrominated diphenyl ethers (PBDEs) by human hepatocytes in vitro. Environ. Heal. Persp., 117, 197, 2009.
11. ZHANG F., LU G., LIU J., YAN Z., ZHANG Z. Bioaccumulation, distribution and metabolism of BDE153 in the freshwater fish Carassius auratus after dietary exposure. Ecotox. Environ. Saf., 108, 16, 2014.

12. BRAEKEVELT E., TITTLEMIER S., TOMY G. Direct measurement of octanol-water partition coefficients of some environmentally relevant brominated diphenyl ether congeners. Chemosphere, 51, 563, 2003.

13. QIU X., MERCADO-FELICIANO M., BIGSBY R., HITES $\mathrm{R}$. Measurement of polybrominated diphenyl ethers and metabolites in mouse plasma after exposure to a commercial pentabromodiphenyl ether mixture. Environ. Heal. Persp., 115, $1052,2007$.

14. NAKARI T., HUHTALA S. Comparison of toxicity of congener-153 of PCB, PBB, and PBDE to Daphnia magna. Ecotox. Environ. Saf., 71, 514, 2008.

15. LINARES V., BELLÉS M., DOMINGO J. Human exposure to PBDE and critical evaluation of health hazards. Arch. Toxicol., 89, 335, 2015.

16. YUAN Y., MEEKER J., FERGUSON K. Serum polybrominated diphenyl ether (PBDE) concentrations in relation to biomarkers of oxidative stress and inflammation: The national health and nutrition examination survey 2003-2004. Sci. Total Environ., 575, 400, 2017.

17. VIDAL-LIÑÁN L., BELLAS J., FUMEGA J., BEIRAS R. Bioaccumulation of BDE-47 and effects on molecular biomarkers acetylcholinesterase, glutathione-S-transferase and glutathione peroxidase in Mytilus galloprovincialis mussels. Ecotoxicology, 24, 292, 2015.

18. CHEN L., YU K., HUANG C., YU L., ZHU B., LAM P., LAM J., ZHOU B. Prenatal transfer of polybrominated diphenyl ethers (PBDEs) results in developmental neurotoxicity in zebrafish larvae. Environ. Sci. Technol., 46, 9727, 2012.

19. OLIVEIRA M., RIBEIRO A., HYLLAND K., GUILHERMINO L. Single and combined effects of microplastics and pyrene on juveniles (0+group) of the common goby Pomatoschistus microps (Teleostei, Gobiidae). Ecol. Indic., 34, 641, 2013.

20. KUIPER R., BERGMAN Å., VOS J., VAN DEN BERG M. Some polybrominated diphenyl ether (PBDE) flame retardants with wide environmental distribution inhibit TCDD-induced EROD activity in primary cultured carp (Cyprinus carpio) hepatocytes. Aquat. Toxicol., 68, 129, 2004.

21. GHOSH R., LOKMAN P., LAMARE M., METCALF V., BURRITT D., DAVISON W., HAGEMAN K. Changes in physiological responses of an Antarctic fish, the emerald rock cod (Trematomus bernacchii), following exposure to polybrominated diphenyl ethers (PBDEs). Aquat. Toxicol., 128-129, 91, 2013.

22. KUIPER R., MURK A., LEONARDS P., GRINWIS G., VAN DEN BERG M., VOS J. In vivo and in vitro Ah-receptor activation by commercial and fractionated pentabromodiphenylether using zebrafish (Danio rerio) and the DR-CALUX assay. Aquat. Toxicol., 79, 366, 2006.

23. GUILHERMINO L., LOPES M., CARVALHO A., SOARED A. Inhibition of acetylcholinesterase activity as effect criterion in acute tests with juvenile Daphnia magna. Chemosphere, 32, 727, 1996.

24. LU G., WANG C., ZHU Z. The dose-response relationships for EROD and GST induced by polyaromatic hydrocarbons in Carassius auratus. B. Environ. Contam. Tox., 82, 194, 2009.

25. MARKLUND S., MARKLUND G. Involvement of the superoxide anion radical in the autoxidation of pyrogallol 
and a convenient assay for superoxide dismutase. Eur. J. Biochem. 47, 469, 1974.

26. BRADFORD M. A rapid and sensitive method for the quantitation of microgram quantities of protein utilizing the principle of protein-dye binding. Anal. Biochem., 72, 248, 1976

27. BULL K., BASU N., ZHANG S., MARTIN J., BURSIAN S., MARTIN P., CHAN L. Dietary and in utero exposure to a pentabrominated diphenyl ether mixture did not affect cholinergic parameters in the cerebral cortex of ranch mink (Mustela vison). Toxicol. Sci., 96, 115, 2007.

28. HAN Z., LV C., ZHENG Z. Toxicological effects of PBDEs on Carassius aurats. Chinese J. Geochem., 29, 217, 2010.

29. US EPA. SCE policy issues related to the food quality protection act. Office of pesticide programs science policy on the use of cholinesterase inhibition for risk assessment of organophos-phate and carbamate pesticides. Federal register $63,1998$.

30. LI Z., LU G., YANG X., WANG C. Single and combined effects of selected pharmaceuticals at sublethal concentrations on multiple biomarkers in Carassius auratus. Ecotoxicology, 21, 353, 2012.

31. CHEN G., KONSTANTINOV A., CHITTIM B., JOYCE E., BOLS N., BUNCE N. Synthesis of Polybrominated diphenyl ethers and their capacity to induce CYP1A by the Ah receptor mediated pathway. Environ. Sci. Technol., 35, 3749, 2001.

32. XIE Z., LU G., QI P. Effects of BDE-209 and its mixtures with BDE-47 and BDE-99 on multiple biomarkers in Carassius auratus. Environ. Toxicol. Phar., 38, 554, 2014.

33. HIGGINS L., HAYES J. Mechanisms of induction of cytosolic and microsomal glutathione transferase (GST) genes by xenobiotics and pro-inflammatory agents. Drug Metab. Rev., 43, 92, 2011.

34. ROBERTS S., NOYES P., GALLAGHER E., STAPLETON H. Species-specific differences and Structure-Activity Relationships in the debromination of PBDE congeners in three fish species. Environ. Sci. Technol., 45, 1999, 2011.

35. NOYES P., KELLY S., MITCHELMORE C., STAPLETON $\mathrm{H}$. Characterizing the in vitro hepatic biotransformation of the flame retardant BDE 99 by common carp. Aquat. Toxicol., 97, 142, 2010.

36. LIN T., YU S., CHEN Y., CHEN W. Integrated biomarker responses in zebrafish exposed to sulfonamides. Environ. Toxicol. Pharmacol., 38, 444, 2014.

37. LU G., QI P., CHEN W. Integrated biomarker responses of Carassius auratus exposed to BDE-47, BDE-99 and their mixtures. Int. J. Environ. Res., 7, 807, 2013.

38. LI Z., ZLABEK V., GRABIC R., LI P., MACHOVA J., VELISEK J., RANDAK T. Effects of exposure to sublethal propiconazole on the antioxidant defense system and $\mathrm{Na}^{+}-\mathrm{K}^{+}$-ATPase activity in brain of rainbow trout, Oncorhynchus mykiss. Aquat. Toxicol., 98, 297, 2010.

39. JI C., WU H., WEI L., ZHAO J., LU H., YU J. Proteomic and metabolomic analysis of earthworm Eisenia fetida exposed to different concentrations of 2,2',4,4'-tetrabromodiphenyl ether. J. Proteomics, 91, 405, 2013.

40. LIU J., LU G., YANG H., YAN Z., WANG Y., WANG P. Bioconcentration and metabolism of ketoconazole and effects on multi-biomarkers in crucian carp (Carassius auratus). Chemosphere, 150, 145, 2016. 